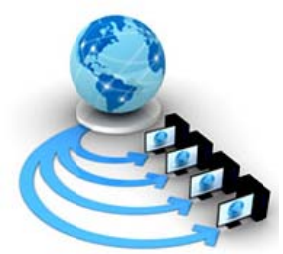

Volume 9, No. 2, March-April 2018

International Journal of Advanced Research in Computer Science

RESEARCH PAPER

\author{
Available Online at www.ijarcs.info
}

\title{
HIDDEN SECURITY FEATURES FOR THE RECOGNITION OF FAKE CURRENCY
}

\author{
B. Hari chandana \\ Scholar in the Dept of Computer Science \& Technology, \\ S.K.U, Anantapuram, India
}

\author{
K. Lavanya \\ Scholar in the Dept of Computer Science \& Technology, \\ S.K.U, Anantapuram, India
}

\author{
Prof.T.Bhaskara Reddy \\ Professor in the Dept of Computer Science \& Technology \\ S.K.U, Anantapuram, India
}

\begin{abstract}
Currency and counterfeiting are two different aspects of every economy .The growing hazard of mock or fictitious currency is one of the serious issues in India and also world-wide. A number of advanced security features have been presented in the Indian currency notes in order to protect them from counterfeit. In this paper, recognition of currency is analyzed and also represented a wide review of the literature techniques related to Indian Currency Detection. The note is checked by using image processing techniques like image acquisition, preprocessing and image enhancement. The main aim of image enhancement is to identify the secret information that is hidden which cannot be visible to eye. It improves the visual appearance of a currency for human viewing, by removing blurring and noise, increasing contrast, and revealing details. The objective of this paper is to detect hidden information that are invisible to eye which help to identify the fake note.
\end{abstract}

Keywords: Hidden, counterfeit, Invisible, OCR.

\section{INTRODUCTION}

The main objective of the study is to specify about several security features of the highest denomination note introduced in the year 2016.Counterfeit money is imitation currency produced without the legal sanction of the state or government. Producing or using fictitious money is a form of fraud or forgery. Fake Indian currency note (FICN)[1] is term to refer a fake currency notes circulated in the Indian economy. As There are so many advanced technologies ,it became very easy to print mock currency. In order to curb these illegal activities of the counterfeit ,it is important for the people to have idea about various security features that are present in the Indian currency notes.The Financial Action Task Force (FATF) report of 2013 found that the Indian rupee was the ninth most counterfeited currency in terms of its value and stood third in terms of the number of FICN detected around the world.. This is probably because of the fact that humans are always looking at ways to make some quick money and become rich. Just like every other currency notes, currency notes in India are also counterfeited for different purposes. With the advent of technology, making fake Indian notes has become even easier. .

1.1 Impact of fake currency:

The issue of fake Indian currency is a huge problem that's been growing in recent years. Counterfeiters are becoming so clever and the newest notes are made so well, it's difficult to identify them. It's estimated that four out of every 1,000 notes in circulation in India are fake. Fake notes are even found in cash withdrawn from ATM machines at banks in India The impact of FICN ON INDIAN ECONOMY are Anti-national activities, Currency inflation, Non-reimbursement by banks, Dumping of cheaper products, Black marketing, Financial Management.

The following is the table representing the data regarding the number of Counterfeit Notes detected in the year 2015-2016[2].The number of counterfeit notes detected at bank branches and the Reserve Bank offices has been constantly increasing year to year. 
Table 1: Counterfeit Currency Detected, 2015-2016

\begin{tabular}{|l|l|l|l|l|l|}
\hline \multicolumn{7}{|c|}{ Counterfeit Currency Detected, 2015-2016 } \\
\hline Denomination & $\begin{array}{l}\text { Counterfeit } \\
\text { Notes } \\
\text { Circulation in }\end{array}$ & $\begin{array}{c}\text { Counterfeit } \\
(\%)\end{array}$ & $\begin{array}{c}\text { Counterfeit } \\
\text { Value }\end{array}$ & Total Value \\
\hline 2,5 & 2 & 11,627 million & 0 & Rs 7 & $4,069.1$ crores \\
\hline 10 & 134 & 32,016 million & 0 & Rs 1342 & 32,015 crores \\
\hline 20 & 96 & 4,924 million & 0 & Rs 1920 & 9,848 crores \\
\hline 50 & 6453 & 3,890 million & 0.0000017 & Rs 322650 & 19,452 crores \\
\hline 100 & 221447 & 15,779 million & 0.000014 & Rs 2.21 crores & $1,57,780$ crores \\
\hline 500 & 261695 & 15,709 million & 0.0000167 & Rs 13.09 crores & $7,85,350$ crores \\
\hline 1000 & 143099 & 6,326 million & 0.0000226 & Rs 14.31 crores & $6,32,600$ crores \\
\hline
\end{tabular}

On November 18th 2016, the National Crime Records Bureau submitted a report to Lok Sabha on fake currency notes seized by police and other enforcement agencies for the year 2013 to 2016 (up to 30th September)

Table 2: Comparingng Counterfeit Currency Year wise (2013-2016)

\begin{tabular}{|l|l|l|}
\hline Year & $\begin{array}{l}\text { Total no. of pieces of } \\
\text { notes (for all } \\
\text { denomination) }\end{array}$ & $\begin{array}{l}\text { Total value(in } \\
\text { millions) }\end{array}$ \\
\hline 2013 & 846966 & 429.02 \\
\hline 2014 & 801528 & 405.80 \\
\hline 2015 & 886058 & 438.34 \\
\hline 2016 (30th sep) & 574176 & 277.94 \\
\hline
\end{tabular}

\section{Counterfeit Currency Detected ,2013- 2016}

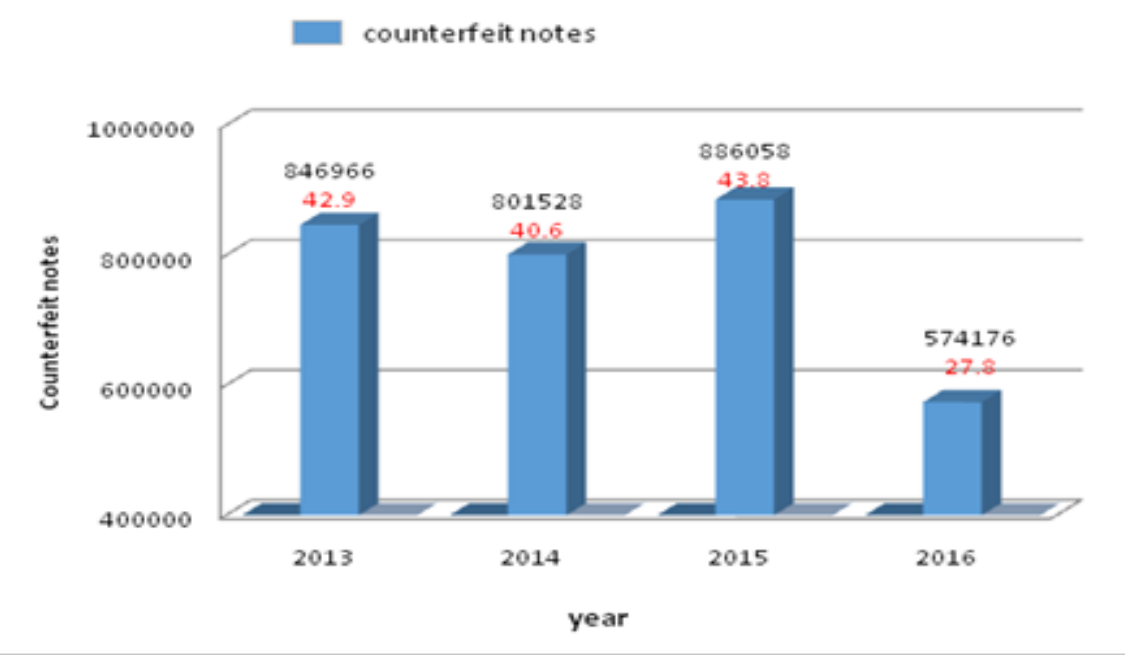

Fig 1.1: Counterfeit Currency/crores in 2013-2016 


\section{SYSTEM OVERVIEW:}

2.1 New Security Features of Rs. 2000 notes:

India has introduced the new currency note of Rs. 2000 which is the highest currency in circulation in Indian economy. The new currency note has led to erode the old

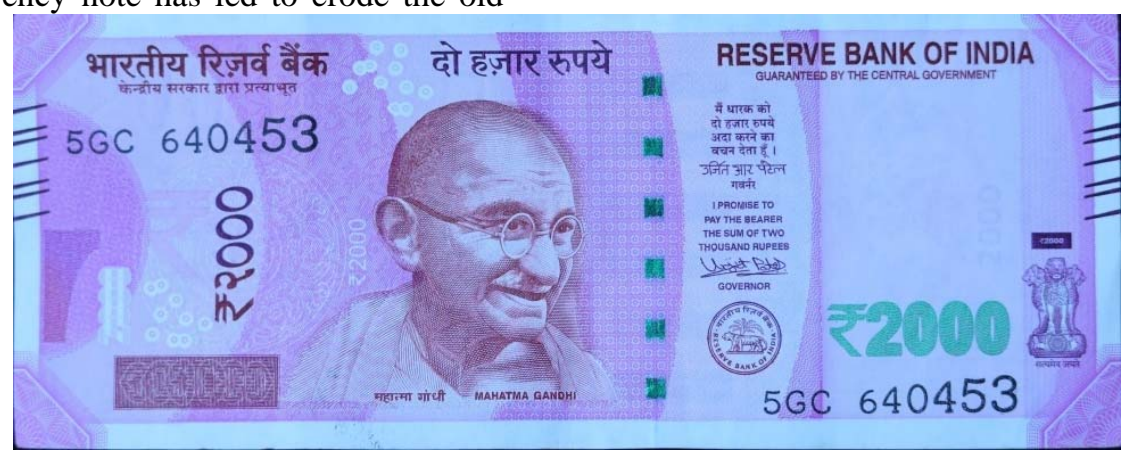

Figure 2a:- Showing identifying features of Rs. 2000 currency of front side

\section{Size and Layout:}

The size of Rs. 2000 note is $66 \mathrm{~mm} \times 6 \mathrm{~mm}$ with magenta coloured, shorter than the old notes. The front side of the note has 11 different typefaces, written in 14 sizes and 12 weights. The back side has 6 (without counting the various scripts), written in 11 sizes and 9 weights.

Obverse:

\section{See through register:}

The see- through feature, a different design on each denomination, is located on both sides of the note. On one side it is hollow, and on the other side it is filled up It is written horizontally just along the micro lettering and above the latent image on the left side of currency. It looks like one single design when seen against light.

\section{Latent image:}

A latent image is safety feature that is covered with in the note .It becomes visible only when it is held horizontally at eye level. The obverse side comes with a horizontal band towards the down left of the currency and encompasses a latent image.

$>$ Denominational numeral of 2000 in Devanagari.

$>$ Potrait of Mahatma Gandhi present at the centre of note.

\section{$>$ Micro lettering:}

Micro letters are minute engravings which can be read under magnifying lens. On Indian banknotes of denominations Rs. 500 and 2000 have micro letters 'RBI' and '2000'. The word RBI is printed using this technique between the vertical band and Mahatma Gandhi portrait.

\section{$>$ Security thread:}

Security thread is $3 \mathrm{~mm}$ wide strip ,usually 6 'windowed' .It reads three words "RBI","BHARAT","2000" imprinted on it blue on being held at an angle and tilted.

> Guarantee Clause, Governor's signature with Promise Clause and RBI emblem towards right. These are printed using Intaglio printing.

\section{$>$ Water marking:} alternatively with its colour changing from green to notes of Rs.500 and Rs1000 and collapsed the whole Indian financial system
Watermark is an identifying image or pattern in paper that appears as various shades of lightness when viewed by transmitted light. The new note 2000 has multidirectional anti scan lines which can be viewed with a help of magnifying glass. When the note is held against light, Mahatma Gandhi's image is visible at the centre of the window and the "electrolyte mark" in numeral " 500 " or "2000" appears vertically on the left side in this section. The various watermarks in 2000 note are

a) Mahatma Gandhi

b) $2 \mathrm{~K}$ Watermark

c) RBI Watermark

d) 2000 Watermark

e) Electrotype Watermark

$>$ Currency serial number:

Number panels with numerals tends to increase from left to right while the first three alpha numeric characters remains constant in size. The banknotes have optical fibres. Both can be seen when the banknotes are seen under ultra-violet lamp.

$>$ Optically variable ink:

optical variable ink(OVI) is a shading moving ink that reflect different wavelengths in white light in an unexpected way. The ink shows two unmistakable hues relying upon the edge the note is seen at. The shade of these numerals seems green when the note is held level and would change to blue held at an edge.

$>$ Ashoka Pillar image on the right..

$>$ Identification Mark:

In case of $€ 500$ banknote a circle and in case of $€ 2000$ bank note a horizontal rectangle appears with raised print above the Ashoka Pillar Emblem. Which can be felt by touch, that helps the visually impaired to identify the denomination of the banknotes 
> Seven angular bleed lines on upper left and right hand edges of the notes to aid visually impaired.

\section{$>$ Fluorescence:}

Fluorescent ink is used to print number panels in the currency notes. The bank notes also have dual coloured optical fibres that are randomly distributed on both the obverse and reverse of the currency note .These fibres, only visible when the note is viewed under a UV trans-illuminator.

Reverse side:

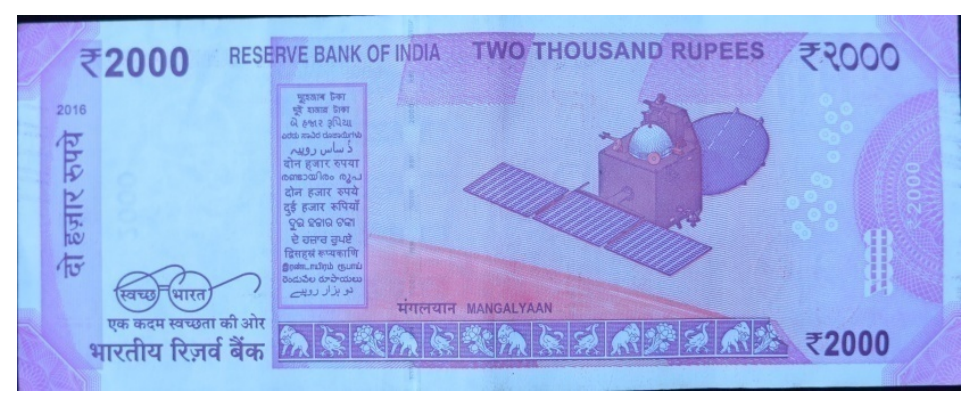

On the reverse side of the note 2000,

$>$ The note will have year when it is printed.

$>$ The swachh Bharat logo with spectacles of Mahatma Gandhi written on the two glasses with the bridge of the spectacles in National Tricolour signifies the entire nation uniting to achieve the vision of Mahatma for a Clean India.

$>$ Language panel displaying the denomination of 15 of the official languages of India. The languages are displayed in alphabetical order.

$>$ The new denomination has the motif of the Mangalyaan on the reverse, depicting the country's first Venture into the interplanetary space, India has now become the third country to commemorate its Success in space on its current paper currency.

$>$ Geometric patterns that exhibits designs aligning with the overall colour scheme.

$>$ Motifs of elephant, peacock and lotus are printed on the reverse side of note.

\subsection{LITERATURE SURVEY:}

From the literature, it is revealed that many researchers have done work on the identification of fake currency. In the year 2008, Yoshida et.al. [3] ,have studied the Bangladesh currency and designed a machine based system for Identification of Bangladeshi bank notes. The proposed system is based on basically denominations of five hundred and one hundred taka. In proposed system, authors first captured the image of note through scanner then processed in microcontroller PIC-16F648A. After micro controlling they determine the validity of note based on some characters on the OCR technique of scanned Image. The success rate of proposed system of counterfeit detection with properly scanned image is $100 \%$ and average processing image is 250 milliseconds.

Hassanpour et. al. [4] ,have proposed a new technique of paper currency recognition which is based on three characteristics of paper currencies including size, colour and texture. By using Image histogram, the different colour in paper currency is compared to reference paper currency
Vora et.al. [5], have designed an algorithm for currency detection based on feature extraction methods and used two dimension discrete wavelet transform (2D DWT) which has used to develop a currency recognition system after the pre-processed of system with example of serial number feature method by implementing the OCR technique to found better results.

In 2014.Binod Prasad Yadav et.al[6], proposed Indian currency recognition through identification mark and serial number detection. This process is dove by using image processing technique.

B.Sai Prasanthi et.al[7], proposed recognition of fake currency with image processing techniques. Six characteristics of Indian paper currency are detected. The characteristic feature is compared with fake currency.

\section{IMAGE PROCESSING:}

Image processing is the study of an algorithm that takes an image as input and returns an image as output. It includes image display and printing, image editing and manipulation, image enhancement. Image processing techniques are often used to improve the visual quality of synthesized images like Image enhancement, noise removal, restoration, feature detection, compression. Image preprocessing is used for operations on images at the lowest level of abstraction. The pre-processing modifies the brightness and contrast of the image and remove noise on the image and improve quality of image.

\subsection{Proposed system:}

In the proposed system, currency features such as watermark, security thread, Fluorescence, Identity Mark, optical variable ink etc.; are used for currency verification. The Fig describes flowchart for Currency recognition 


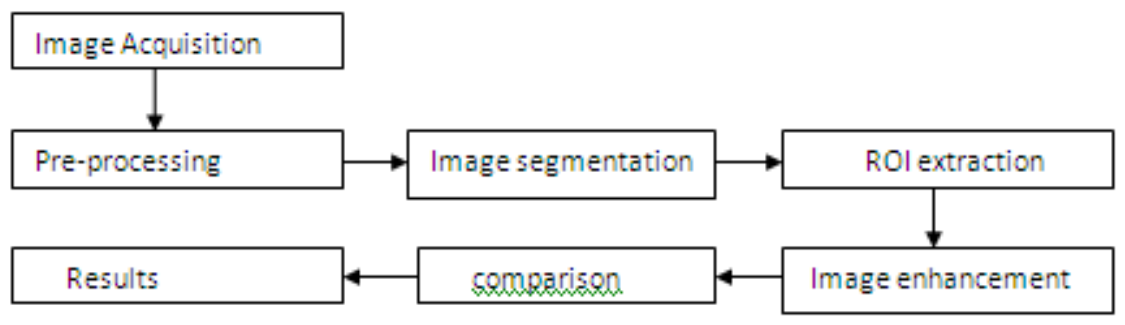

Fig 3.1a: Flow chart of currency recognition and verification system

\subsubsection{Image acquisition:}

An image can be obtained by a range of different device's ,together with cameras or scanner. The most effective precaution we need to take is, try and hold a controlled environment so that the outside elements cannot affect the characteristic values..

\subsubsection{Image Pre-processing:}

Preprocessing tasks are required to improve the image analysis, which improves the extraction of future processing. In this specific case, preprocessing tasks include case, preprocessing operations involve, noise removal by using filters, blurring, color blurring RGB to HSV conversion. These tasks help us in detecting boundaries, cropping the ROI and calculating color .Image processing includes mainly two parts

- Image adjusting

- Image smoothening(removing noise)

Image adjusting is done with the help of image interpolation. Interpolation is the technique mostly used for tasks such as zooming, rotating, and shrinking. When using an advanced camera or scanner to perform image acquisition, some noise will be displayed on the image. Image noise is the arbitrary variation of brightness in the images.

When operating smoothing process on a pixel, the neighbour of the pixel is utilized to do some changing after that another estimation of the pixel is made.. In an image processing, smoothing of a data set by suppressing noise means, to create an approximating function that attempts to capture important patterns in the data.

\subsubsection{Segmentation:}

Image segmentation is a way of dividing an image in to distinct regions.(sets of pixels, otherwise super-pixels). The objective of segmentation is to decompose an image into parts that are meaningful with respect to a particular application. Image segmentation is mostly used to find objects and edges in images.

3.1.4 Image enhancement:

The key goal of image enhancement is to process to transform an image so that the outcome is more appropriate than the original image for a specific application. Image resizing is essential when we want to increase or decrease the aggregate number of pixels. Resolution is the ability to resolve the spectral features of an object with specific boundaries. The spatial resolution refers to the number of pixels utilized in construction of digital image. So it depends on the number of pixels and the area in which these pixels are resolved .Image enhancement is the modification of image by changing the pixel brightness values to improve its visual impact In image enhancement, the goal is to accentuate certain image features for subsequent analysis or for image display .Image enhancement involves a collection of techniques that are used to improve the visual appearance of an image, or to convert the image to a form which is better suited for human or machine interpretation.

3.2 Tools for Counterfeit Document Detection

Available tools for counterfeit detection/document verification run the full spectrum, from the overly simplistic to the extremely complex. The choice of which is the right tool to use depends entirely upon the circumstances that define the exposure to fraud at each point of transaction .In reviewing the types of device available, we have segmented them into two primary categories;

- Visible Verification

- Invisible Verification

\subsubsection{Visible Verification:}

When conducting visible document inspection, the acceptor is attempting to verify that certain visible security features are present on the currency. The first and most important state is OCR that has to be passed to be a genuine note

$>$ Optical Character Recognition

OCR, Optical Character Recognition, is developed to translate scanned images of handwritten, typewritten or printed text into machine-encoded text. A lot of OCR software have been developed. One of them is, Tesseract, originally developed as proprietary software at Hewlett Packard between 1985 and 1995, now sponsored by Google, is considered to be one of the most accurate open source OCR engine currently available. It is capable of recognizing text in variety of languages in a binary image format 
Table 3.2.1aVisible OCR Recognition

\begin{tabular}{|c|l|l|c|}
\hline Input & Software tuning & Hardware requirement & Result \\
\hline $\begin{array}{l}\text { INR 2000 containing character } \\
\text { region } \\
56 C \quad 640453\end{array}$ & 1.Brightness :90\% & $\begin{array}{l}\text { Highly USB 2.0 } \\
\text { camera }\end{array}$ & 5GC 640453 \\
\cline { 2 - 3 } & 2.Contrast : :100\% & & \\
\cline { 2 - 3 } & 3.sharpness : :100\% & & \\
\hline
\end{tabular}

\subsubsection{Invisible Verification :}

Non-visible "covert" features are, by definition, designed specifically to not be visible to the human eye under normal conditions. For this reason, in order to verify the presence of such features, a tool or device must be used to enable the user to verify them. There are a number

Of different techniques for creating covert features.

\section{Micro Letter Printing :}

As the name suggests, micro printing is a technique in which extraordinarily fine detailed printing is performed on a document. In the case of currency notes, micro printed features are typically words printed in characters too small for the naked eye to see. As the example, the newest design 2000 banknote contains several different areas on the note where different micro printed security features can be found.

Table 3.2.1b Invisible Micro Letter Recognition

\begin{tabular}{|c|c|c|c|c|}
\hline S.no & Input & Software tuning & $\begin{array}{l}\text { Hardware } \\
\text { requirement }\end{array}$ & Result \\
\hline \multirow[t]{3}{*}{1.} & $\begin{array}{ccc}\text { INR } & 2000 \text { containing } \\
\text { 'RBI' } & \text { Micro letter at }\end{array}$ & 1.Brightness : $90 \%$ & \multirow{3}{*}{$\begin{array}{l}\text { Highly USB } 2.8 \\
\text { Camera }\end{array}$} & \\
\hline & Gallu & 2.Contrast $: 100 \%$ & & \\
\hline & nis & $\begin{array}{l}\text { 3.sharpness : } 100 \% \\
\text { 4.Enhancement: } 80 \%\end{array}$ & & Accuracy:100 \% \\
\hline \multirow[t]{3}{*}{2.} & \multirow{3}{*}{$\begin{array}{l}\text { INR } 2000 \\
\text { containing 'India' Micro } \\
\text { letter at collar region }\end{array}$} & 1.Brightness : $90 \%$ & \multirow{3}{*}{$\begin{array}{l}\text { Highly USB } \\
\text { camera }\end{array}$} & \multirow{3}{*}{ Accuracy:100\% } \\
\hline & & 2. Contrast $\quad: 100 \%$ & & \\
\hline & & $\begin{array}{l}\text { 3.sharpness : : } 100 \% \\
\text { 4. Enhancement: } 80 \%\end{array}$ & & \\
\hline
\end{tabular}

\subsection{Overall algorithm:}

The scheme of proposed approach is to design a method that can be implemented on many distinct currency notes that has good accuracy and performance.
1. Scan the currency note by using any desirable channels like high USB camera or scanner.

2. By using Image Preprocessing principles the features of the image are extracted for processing.

3. next the image is divided into segments to extract the attributes of the image. 
4. Select a particular region from the currency and perform enhancement techniques to reveal the hidden information.

5. compare the original currency features with the fake currency feature.

6. If they match the currency is original otherwise fake.

\section{RESULTS AND DISCUSSION:}

The whole is different from existing fake detection tools like chemical property based tools, color density measuring tools and most importantly single feature based tool like UV light pen tool. Different parameters have been selected for getting the optimized result. Since the image contains the number of segmented parts therefore we can apply security measures to any region of Interest (ROI) to these parts. We have compared the hidden features to check the two notes. Next we have acquired two notes that have been in RGB colour and converted into the Hue-saturationvalue (HSV) format. By this process the complete image has been separately looked each Red, Green, Blue component and these two images are also represented below.A pictorial comparison of the selected features based on the outputs between genuine and fake notes are as follows

Table I :Micro Letter Test

\begin{tabular}{|l|c|c|}
\hline $\begin{array}{c}\text { HIDDEN } \\
\text { MICROLETTER } \\
\text { RECOGNITION } \\
\text { (Genuine Note) }\end{array}$ & Input image & Output image \\
\hline $\begin{array}{c}\text { MICROLETTER } \\
\text { RECOGNITION } \\
\text { (Fake Note) }\end{array}$ & Input image & Output image \\
& & \\
\hline
\end{tabular}

Table II : HSV Test

\begin{tabular}{|c|c|c|}
\hline $\begin{array}{c}\text { HSV CONVERSION } \\
\text { (Genuine Note) }\end{array}$ & Input image \\
\hline $\begin{array}{c}\text { HSV CONVERSION } \\
\text { (Fake Note) }\end{array}$ & Input image & Output image \\
\hline
\end{tabular}

\section{CONCLUSION AND FEATURE EXTRACTION :}

Due to the lack of knowledge it became east to cheat the common man with the fake currency notes. In this paper, the verification of Indian currency is depicted by implementing Image processing techniques. The present study gives detailed description of various security features that are included in the Indian currency note. This study reveals the hidden features by performing pre-processing and feature extraction technique and thus prove the accuracy of fake detection system.

There are similar hidden features in the other currency notes like €500, €200, €50 which can also be detected and this can be applied to foreign currency ( Dollar, Euro etc;). 


\section{REFERENCES:}

[1] http:॥www.pressreader.com

[2] Syed Mahmood Ali ,Fahmeeda Faiyaz,"Denomization Impact on Black Money, Counterfeit Currency and Corruption"(2250-0758) Volume-7 Issue-3,May-June 2017.

[3] Z. Ahmed, S. Yasmin, M. N. Islam, R. U. Ahmed, "Image processing based Feature extraction of Bangladeshi banknotes," Proc. Software, Knowledge, Information Management and Applications (SKIMA), pp.1-8, 18-20 Dec. 2014.

[4] H. Hassanpour ,A. Yaseri, G. Ardeshiri , Feature Extraction for Paper Currency Recognition, IEEE Transactions, 1-4244 0779-6/07,2007.

\section{AUTHORS PROFILE}

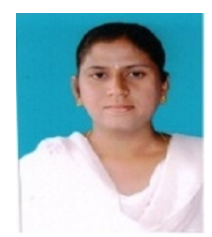

Mrs.B.Harichandana is research scholar in the Department of Computer Science and Technology at S.K.University, Anantapur. She acquired M.Sc in Computer Science from S.K. University, Anantapur. She has 10 years of experience in teaching. Her research interest is in the field of Image Processing.

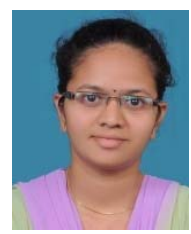

Miss.K.Lavanya is research scholar in the Department of Computer Science and Technology at S.K.University, Anantapur. She acquired M.Sc in Computer
[5] Komal Vora, Ami Shah, Jay Mehta, A Review Paper on Currency Recognition System, International Journal of Computer Applications (0975 - 8887) Volume 115 - No. 20, April 2015.

[6] Binod Prasad Yadav, C. S. Patil and R. R. Karhe and P. H. Patil, "Indian Currency Recognition and Verification System Using Image Processing,” International Journal of Advanced Research in Computer Science and Software Engineering, Volume 4, Issue 12, December 2014.

[7] B.Sai Prasanthi, D. Rajesh Setty , Indian Paper Currency Authentication System using Image processing International Journal of Scientific Research Engineering \& Technology (IJSRET), ISSN 2278 - 0882.

Science from S.K. University, Anantapur. She has 10 years of experience in teaching .Her research interest is in the field of Image Processing.

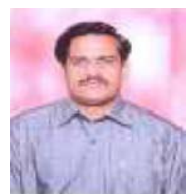

Dr. T. Bhaskara Reddy is a Professor in Department of Computer Science and Technology at S.K. University, Anantapur , A.P. He holds the post of Deputy Director of Distance education at S.K.University and he was also the CSE Coordinator of Engineering at S.K.University. He has completed his M.Sc and $\mathrm{Ph} . \mathrm{D}$ in computer science from S.K.University. He has acquired M.Tech from Nagarjuna University. He has been continuously imparting his knowledge to several students from the last 17 years. He has published 47 National and International publications. He has completed major research project(UGC). 